\title{
Fertilização orgânica em sistemas silvipastoris
}

\author{
Stella Cristiani Gonçalves Matoso ${ }^{1 *}$, Ana Karina Dias Salman² \\ ${ }^{1}$ Instituto Federal de Rondônia, Departamento de Ciências Agrárias, Rodovia BR 435, km 63, Zona Rural, C P 51, CEP: 76.993-000, Colorado do Oeste, RO, Brasil \\ 2Embrapa Rondônia, Rodovia BR 364, Km 5,5, Zona Rural, C P 127, CEP: 76815-800, Porto Velho, RO, Brasil
}

\author{
"Autor correspondente: \\ stella.matoso@ifro.edu.br \\ Termos para indexação: \\ Adubação \\ Solo \\ Sistema Agrosilvopastoril
}

Index terms:

Fertilization

Soil

Agroforestry systems

Histórico do artigo:

Recebido em 12/07/2015

Aprovado em 21/10/2016

Publicado em 30/12/2016

doi: 10.4336/2016.pfb.36.88.982
Resumo - Diante das exigências socioambientais atuais, cresce o interesse e a necessidade por sistemas de produção agrícolas conservacionistas, como os sistemas silvipastoris. A integração de espécies arbóreas e forrageiras torna o sistema complexo, podendo ocorrer interações indesejáveis entre as espécies, como a competição por nutrientes. Para não exaurir os nutrientes do solo e obter bons rendimentos das culturas é necessário manejo adequado da adubação. Com isso, objetivou-se caracterizar o estado da arte das pesquisas sobre o efeito da adubação orgânica em sistemas silvipastoris. Foi possível constatar que o manejo da adubação orgânica é complexo, devido às características intrínsecas aos resíduos orgânicos, bem como às relações ecológicas no próprio sistema. No entanto, pode suprir e/ou diminuir a necessidade de calagem e fertilização mineral com longo efeito residual e rendimentos satisfatórios, tanto do componente arbóreo, quanto do forrageiro. Constatou-se, também, que mais pesquisas são necessárias com ênfase na variação de adubos orgânicos, técnicas de manejo, arranjos, espécies e condições edafoclimáticas.

\section{Organic fertilization in silvopasture systems}

\begin{abstract}
Given the current environmental requirements has increased the interest and the need for conservationist production systems, such as silvopasture. The integration of trees and forages species turns it into a complex system and can cause undesirable interactions among species, such as competition for nutrients. To avoid soil nutrients depletion and to achieve good crop yields it is necessary to need manage fertilization properly. This work aimed to characterize the state of the art of researches on the effect of organic fertilizer in silvopasture systems. It was observed that organic fertilizer management is complex due to intrinsic characteristics of the organic waste and the ecological relationships within the system. However, it can supply and/or reduce the need for liming and mineral fertilization with long residual effect and satisfactory yields of both trees and forages components. It was also noted that more researches is needed emphasizing wide variation of organic fertilizers, management techniques, species and environmental conditions.
\end{abstract}

\section{Introdução}

A necessidade de conservação dos recursos naturais e a crescente demanda de produção de alimentos e energia são aspectos antagônicos e urgentes para a sociedade atual. Diante disso, vem aumentando o interesse por sistemas produtivos conservacionistas, dentre os quais se podem destacar os sistemas silvipastoris, que consistem em modalidades de sistemas agroflorestais, e se caracterizam por integrar componentes arbóreos, herbáceos e animais escalonados no espaço e/ou no tempo (Nair, 1989; Oliveira et al., 2012).

A integração de duas ou mais espécies em uma mesma área pode ser permanente ou temporária. Ambas trazem inúmeros benefícios, tais como maior conforto térmico para os animais, melhoria nas características de fertilidade do solo e controle de erosão, maior aproveitamento da água meteórica, melhoria da disponibilidade e qualidade 
da forragem, maior conservação do solo, da água e da biodiversidade e diversificação da renda da propriedade rural. Por outro lado, tornam o sistema mais complexo, tornando difícil seu planejamento e manejo (Carvalho \& Xavier, 2005; Bernardino \& Garcia, 2009).

No âmbito fitotécnico os principais fatores envolvidos são a competição por água, luz e nutrientes que pode ocorrer entre as plantas. Dentre as três, a competição por água pode ser considerada a menos problemática, devido às diferenças morfológicas entre as espécies arbóreas e forrageiras. As pesquisas concentram-se, principalmente, no efeito do sombreamento que o crescimento das árvores causa nas plantas forrageiras (Bernardino \& Garcia, 2009). No entanto, Andrade et al. (2001) demonstraram que o declínio da produção das espécies forrageiras não decorre apenas da menor incidência de luz, mas também pela falta de adubação de manutenção, principalmente nitrogenada.

A fertilização dos solos se faz fundamental para elevar o rendimento das culturas, seja em cultivo solteiro ou integrado. As adubações de plantio ou formação e de manutenção podem ser realizadas por diversas fontes de nutrientes, minerais, orgânicas e organominerais. $\mathrm{O}$ efeito da adubação sobre as propriedades do solo e desenvolvimento das plantas depende da composição e forma do adubo, do manejo do sistema como um todo e das próprias características edafoclimáticas (Lopes et al., 2004; Havlin, 2005).

À adubação mineral são atribuídas diversas desvantagens, tais como o alto custo de aquisição e transporte, acidificação do solo, principalmente com a adubação nitrogenada, baixa eficiência agronômica, devido aos processos de lixiviação de nutrientes, volatilização da amônia, desnitrificação do nitrato, fixação do fosfato, dentre outros (Lopes et al., 2004; Tasca et al., 2011; Behera et al., 2014; Associação Nacional para Difusão de Adubos, 2016). Por outro lado, os adubos orgânicos, desde que humificados, além de fornecerem macronutrientes primários e secundários, têm potencial para elevar o $\mathrm{pH}$, a capacidade de troca de cátions, o conteúdo de micronutrientes e carbono no solo, diminuir o teor de alumínio disponível e a capacidade de fixação de fosfato, e ainda são de baixo custo e fácil acesso (Andrade et al., 2003; Lal, 2004; Lima et al., 2007; Li \& Johnson, 2016).

A sistematização das informações disponíveis sobre o tema possibilitaria o avanço no âmbito da pesquisa e também do uso e manejo da fertilização orgânica em sistemas silvipastoris. Portanto, objetivou-se caracterizar o estado da arte das pesquisas que avaliaram o efeito da adubação orgânica sobre as propriedades do solo e os componentes vegetais de sistemas silvipastoris.

\section{Resíduos orgânicos como fonte de nutrientes}

O aproveitamento agrícola de resíduos orgânicos tem se apresentado como alternativa para diminuir o volume e o potencial de poluição desses compostos (Teixeira, 2015) e para superar a necessidade de importação de fertilizantes minerais (Associação Nacional para Difusão de Adubos, 2016), além dos efeitos benéficos no solo, como as melhorias nos aspectos físicos, químicos e biológicos.

Na literatura relacionada à adubação de sistemas silvipastoris o resíduo mais utilizado é o lodo de esgoto. Seu uso é realizado também em monocultivo florestal (Eucalyptus grandis) e em pastagens (Brachiaria decumbens) (Barreiros et al., 2007; Araújo et al., 2009). Em sistemas solteiros de espécies florestais e forrageiras são utilizadas ainda a cama de frango e o chorume suíno (Lima et al., 2007; Scheffer-Basso et al., 2008). Entretanto, diversos materiais orgânicos podem constituir um adubo orgânico, de acordo com sua disponibilidade e características químicas, físicas e biológicas (Teixeira, 2015).

Nas Tabelas 1 e 2 pode-se observar a composição química de diferentes resíduos utilizados como adubo orgânico. Em geral, os resíduos orgânicos apresentam $\mathrm{pH}$ próximo à neutralidade e podem constituir fonte de macro e micronutrientes. Geralmente, a dose a ser aplicada é determinada de acordo com a necessidade de adubação de um macronutriente primário, principalmente o nitrogênio (Ferreiro-Domínguez et al., 2011). Concomitantemente, se faz necessário verificar a quantidade fornecida dos demais nutrientes e, em caso de algum se encontrar abaixo da exigência da cultura, 
pode-se realizar a complementação com fontes minerais (López-Díaz et al., 2009).

Tabela 1. Propriedades básicas de resíduos orgânicos utilizados como adubo.

\begin{tabular}{|c|c|c|c|c|c|c|c|c|c|}
\hline \multirow{2}{*}{ Material } & \multirow{2}{*}{ pH } & $\mathbf{N}$ & $\mathbf{P}$ & $\mathbf{K}$ & $\mathbf{C a}$ & Mg & $\mathbf{N a}$ & MS & \\
\hline & & \multicolumn{7}{|c|}{$\mathrm{g} \mathrm{kg}^{-1}$} & \\
\hline Lodo de esgoto $^{1}$ & 5,8 & 27,1 & 5,5 & 2,8 & 10,3 & 14,9 & & 416,7 & Chiaradia et al. (2009) \\
\hline Lodo de esgoto ${ }^{2}$ & 7,1 & 29,7 & 19,9 & 3,0 & 3,0 & 6,2 & 0,7 & 222,7 & Ferreiro-Domínguez et al. (2011) \\
\hline Lodo de esgoto ${ }^{2}$ & 7,5 & 25,4 & 19,6 & 3,9 & 3,2 & 6,8 & 1,2 & 238,2 & Ferreiro-Domínguez et al. (2011) \\
\hline Lodo de esgoto ${ }^{2}$ & 7,0 & 28,2 & 18,7 & 2,7 & 5,2 & 4,4 & 0,6 & 239,9 & Ferreiro-Domínguez et al. (2011) \\
\hline Lodo de esgoto ${ }^{2}$ & 7,5 & 35,0 & 17,8 & 3,5 & 27,1 & 8,4 & 1,5 & 204,7 & Mosquera-Losada et al. (2010) \\
\hline Lodo de esgoto ${ }^{2}$ & 6,9 & 32,1 & 9,3 & 2,5 & 6,7 & 5,4 & 0,8 & 250,0 & Mosquera-Losada et al. (2012) \\
\hline Lodo de esgoto ${ }^{2}$ & 6,9 & 32,1 & 5,2 & 2,5 & 6,9 & 4,3 & 0,2 & 250,0 & Mosquera-Losada et al. (2012) \\
\hline Lodo de esgoto ${ }^{2}$ & 6,9 & 42,3 & 16,5 & 2,6 & 6,9 & 6,5 & 1,4 & 235,0 & Mosquera-Losada et al. (2012) \\
\hline Lodo de esgoto ${ }^{2}$ & 6,3 & 47,0 & 16,0 & 1,0 & 29,2 & 2,2 & 0,5 & 940,0 & Araújo et al. (2009) \\
\hline Lodo de esgoto ${ }^{3}$ & 12,0 & 26,2 & 9,5 & 1,3 & 95,0 & 3,0 & 0,5 & 400,0 & Barreiros et al. (2007) \\
\hline Lodo de laticínio ${ }^{4}$ & & 1,3 & 0,55 & 0,15 & 1,7 & 0,21 & & 250,0 & Rigueiro-Rodríguez et al. (2000) \\
\hline Cama de frango & 7,7 & 22,7 & 1,8 & 27,5 & 32,0 & 4,6 & & 857,4 & Lima et al. (2007) \\
\hline Chorume suíno & 7,7 & 5,0 & 1,6 & 2,5 & & & & & Scheffer-Basso et al. (2008) \\
\hline
\end{tabular}

MS = matéria seca $;{ }^{1}$ material não digerido $;{ }^{2}$ material digerido anaerobiamente; $;{ }^{3}$ método de digestão não mencionado $;{ }^{4}$ resultados expressos em $\mathrm{kg}$ m ${ }^{-3}$.

Tabela 2. Micronutrientes e metais pesados $\left(\mathrm{mg} \mathrm{kg}^{-1}\right)$ contidos em resíduos orgânicos utilizados como adubo

\begin{tabular}{cccccccccc}
\hline Material & $\mathbf{F e}$ & $\mathbf{M n}$ & $\mathbf{Z n}$ & $\mathbf{C u}$ & $\mathbf{C d}$ & $\mathbf{P b}$ & $\mathbf{C r}$ & $\mathbf{N i}$ & \\
\hline Lodo de esgoto & 15.010 & 429,0 & 874,0 & 800,0 & 12,5 & 106,0 & 108,1 & 30,3 & Chiaradia et al. (2009) \\
\hline Lodo de esgoto & 26.000 & 311,7 & 364,7 & 242,8 & 4,4 & 130,6 & 87,9 & 98,7 & Ferreiro-Domínguez et al. (2011) \\
\hline Lodo de esgoto & 13.900 & 358,8 & 748,0 & 195,8 & 10,9 & 78,7 & 81,4 & 142,8 & Ferreiro-Domínguez et al. (2011) \\
\hline Lodo de esgoto & 11.000 & 174,4 & 154,1 & 144,7 & 5,1 & 81,9 & 56,6 & 55,3 & Ferreiro-Domínguez et al. (2011) \\
\hline Lodo de esgoto & 17.900 & 6,1 & $1.248,6$ & 142,7 & 0,7 & 84,4 & 39,4 & 29,4 & Mosquera-Losada et al. (2010) \\
\hline Lodo de esgoto & 19.500 & 228,0 & 821,0 & 244,0 & 5,0 & 203,0 & 39,0 & 21,0 & Mosquera-Losada et al. (2012) \\
\hline Lodo de esgoto & 16.100 & 164,0 & 746,0 & 154,0 & 1,0 & 94,7 & 141,0 & 30,0 & Mosquera-Losada et al. (2012) \\
\hline Lodo de esgoto & 22.900 & 292,0 & 1320,0 & 241,0 & 1,5 & 184,0 & 74,0 & 49,0 & Mosquera-Losada et al. (2012) \\
\hline Lodo de esgoto & 33.793 & 349,3 & $1.230,0$ & 239,8 & 3,3 & 199,6 & 633,8 & 54,7 & Araújo et al. (2009) \\
\hline Lodo de esgoto & 39.200 & 300,0 & 1500,0 & 917,0 & 21,0 & 200,0 & & & Barreiros et al. (2007) \\
\hline LMP & & & $2.800,0$ & $1.500,0$ & 39,0 & 300,0 & $1.000,0$ & 420,0 & (Brasil, 2006) \\
\hline
\end{tabular}


LMP = limite máximo permitido pela legislação brasileira.

Uma das dificuldades de utilizar fontes orgânicas na adubação é determinar o teor do nutriente que será efetivamente mineralizado e disponibilizado às plantas, principalmente no caso do nitrogênio. São necessários, portanto, ensaios prévios de mineralização (Chiaradia et al., 2009) ou utilização de valores médios de outros trabalhos em condições ambientais distintas (Brasil, 2006; Araújo et al., 2009).

Para o lodo de esgoto digerido anaerobiamente, Boeira et al. (2002) obtiveram teor de nitrogênio mineralizável por volta de $31 \%$ do nitrogênio total, estimado pelo modelo exponencial simples em solo de textura argilosa. Chiaradia et al. (2009) encontraram valor de $28 \%$ utilizando lodo de esgoto não digerido em solo de textura argilosa. Em solos arenosos a mineralização do nitrogênio do lodo de esgoto digerido aerobiamente pode alcançar a ordem de 60\% (Giacomini et al., 2015). Esses teores são divergentes daqueles indicados para o cálculo do nitrogênio disponível (mineralizável) pela legislação brasileira (Brasil, 2006), que define valor de $40 \%$ para lodo de esgoto não digerido, $30 \%$ e $20 \%$, respectivamente, para aqueles digeridos aerobia e anaerobiamente e $10 \%$ para lodo de esgoto compostado.

Nesse contexto, Boeira \& Maximiliano (2009) constataram que reaplicações de lodo de esgoto em uma mesma área não afetam a dinâmica de mineralização do nitrogênio. Contudo, a quantidade de nitrogênio aplicada deve ser menor do que a inicial, devido ao teor residual no solo. Caso contrário, podem ocorrer efeitos indesejáveis, como o acúmulo de nitrato e possível lixiviação.

Os adubos orgânicos possuem alto teor de umidade e, consequentemente, baixo conteúdo de matéria seca (Tabela 1). Diante disso, pode se fazer necessária uma etapa prévia de secagem do material (Lima et al., 2007; Araújo et al., 2009) ou o transporte e aplicação de grandes volumes dos resíduos, acarretando elevação do custo energético e econômico da adubação. Por isso, é interessante que o resíduo utilizado como adubo seja abundante e disponível nas proximidades da área de aplicação (Teixeira, 2015).

Por outro lado, o uso de resíduos orgânicos na adubação tem a vantagem de incorporar grandes quantidades de carbono no solo. Portanto, além de evitar a decomposição em locais inadequados, contribui para o aumento do estoque de carbono no solo, que é necessário para elevar a retenção de água e nutrientes, diminuir os riscos de erosão e degradação, melhorar a estrutura do solo e fornecer energia para os microrganismos do solo (Lal, 2004).

Ainda que os resíduos orgânicos sejam fonte de vários elementos essenciais às plantas, também levam em sua composição elementos classificados como metais pesados, que podem ser nocivos às plantas, animais e ao homem. Devido a isso, existe legislação pertinente aos limites máximos de determinados elementos que podem estar contidos em um adubo orgânico, que pode ser nacional ou estadual (Plese, 2015). Na Tabela 2 é possível observar que o lodo de esgoto geralmente não excede os níveis permitidos pela legislação brasileira.

\section{Efeito da adubação orgânica sobre os atributos do solo}

O sistema silvipastoril em si possui influência sobre a fração orgânica do solo e ciclagem de nutrientes. A presença das árvores proporciona deposição gradual de biomassa no solo, aumentando o teor de matéria orgânica e de nutrientes como nitrogênio, cálcio, magnésio, potássio e fósforo em relação aos monocultivos com as mesmas taxas de entrada de nutrientes. Esse efeito é ainda potencializado com o uso de árvores leguminosas. Dentro do arranjo espacial do sistema também podem ser observadas diferenças. Quando o solo é amostrado sob a copa das árvores os teores dos nutrientes são maiores do que em áreas de pastagem distante das árvores (Joffre et al., 1998; Andrade et al., 2002). Entretanto, mesmo com maior capacidade de ciclagem e realocação de nutrientes, o manejo intensivo nos sistemas silvipastoris leva à necessidade de reposição dos nutrientes (Bernardino \& Garcia, 2009).

Nesse sentido, encontram-se trabalhos com adubação orgânica para o fornecimento e reposição de nutrientes no solo em sistemas silvipastoris. Ferreiro-Domínguez et al. (2011) aplicaram, em um solo arenoso da Espanha, $0,100,200$ e $400 \mathrm{~kg}$ de $\mathrm{N} \mathrm{ha}^{-1}$ a partir de lodo de esgoto digerido anaerobicamente, por dois anos consecutivos. A adubação foi realizada em um sistema silvipastoril com um ano de estabelecimento. Além dos dois anos de aplicação, foram avaliadas as propriedades químicas do solo nos dois anos subsequentes. A pastagem foi constituída da mistura de Dactylis glomerata L. var. Artabro, Lolium perenne L. var. Brigantia e Trifolium repens L. var. Huia. As árvores pertenciam à espécie Quercus rubra L.

Os autores constataram que no primeiro ano de 
aplicação houve efeito significativo das doses sobre a capacidade de troca de cátions e saturação por cálcio (\%), sendo que as melhores doses ficaram entre 100 e $200 \mathrm{~kg}$ de $\mathrm{N} \mathrm{ha}^{-1}$. Independentemente das doses, a presença do lodo de esgoto elevou $(\mathrm{p}<0,01)$ o $\mathrm{pH}$ de 5,4 no primeiro ano para 5,72 no quarto. Do mesmo modo, a capacidade de troca de cátions foi aumentada $(\mathrm{p}<0,01)$ de 4,94 para 7,84 $\mathrm{cmol}_{\mathrm{c}} \mathrm{kg}^{-1}$ de solo. A saturação por alumínio e potássio foram maiores $(\mathrm{p}<0,01)$ nos primeiros anos. Para o magnésio não houve diferença $(p>0,01)$ entre os anos avaliados. As demais propriedades químicas não foram avaliadas.

Ferreiro-Domínguez et al. (2014) determinaram as características químicas de um solo de textura média da Espanha cultivado sob sistema silvipastoril. A espécie Pinus radiata foi implantada em 1998 e em 1999 foi semeada a mistura de Lolium perenne var. Brigantia, Dactylis glomerata var. Artabro e Trifolium repens cv. Huia. Nos anos 2000, 2001, 2002 e 2003 foi realizada a adubação com base no teor de $\mathrm{N}$ de lodo de esgoto, aplicando-se 50 e $100 \mathrm{~kg}$ de $\mathrm{N} \mathrm{ha}^{-1}$ na presença e ausência de 2,5 $\mathrm{Mg}$ de $\mathrm{CaCO}_{3} \mathrm{ha}^{-1}$, aplicadas em 1999, e um tratamento sem fertilização. As avaliações foram realizadas em 2004, 2007 e 2009. Foi constatado que o $\mathrm{pH}$, capacidade de troca de cátions, saturação por cálcio, magnésio e potássio do solo foram maiores $(\mathrm{p}<0,01)$ em 2007. A saturação por sódio só se elevou $(\mathrm{p}<0,01)$ no ano de 2009. A saturação por alumínio foi menor (p $<0,01)$ em 2007.

Mosquera-Losada et al. (2012) também comprovaram o efeito residual da adubação com lodo de esgoto em sistema silvipastoril com Pinus radiata na Espanha. Esses autores acrescentaram, ainda, que a contribuição desse tipo de insumo para elevação do $\mathrm{pH}$ superou o calcário ao longo do tempo.

$\mathrm{O}$ efeito da adubação orgânica $\left(320 \mathrm{~kg}\right.$ de $\mathrm{N} \mathrm{ha}^{-1}$ a partir de lodo de esgoto em um único ano de aplicação) e adubação mineral (500 $\mathrm{kg} \mathrm{ha}^{-1}$ da formulação 8:24:16 de $\mathrm{N}: \mathrm{P}_{2} \mathrm{O}_{5}: \mathrm{K}_{2} \mathrm{O}$ em três anos consecutivos) em solo previamente cultivado e solo sob floresta em conjunto com a implantação de diferentes sistemas consorciados e solteiros de árvores (Pinus sp.) e pastagens (mistura de Dactylis glomerata (L.) var. Artabro, Lolium perenne (L.) var. Brigantia, Trifolium repens (L.) var. Huia) foi avaliado por Mosquera-Losada et al. (2010). Os autores observaram que o efeito da adubação mineral e orgânica foi diferenciado tanto para os solos quanto para os sistemas. A propriedade mais influenciada foi o $\mathrm{pH}$ do solo. A adubação orgânica manteve $\mathrm{pH}$ mais elevado ( $\mathrm{p}$ $<0,01)$ que a adubação mineral. Os solos previamente cultivados e os sistemas silvipastoris também obtiveram maior $(\mathrm{p}<0,01)$ teor do $\mathrm{pH}$ do solo, além de maior ( $\mathrm{p}$ $<0,01)$ capacidade de troca de cátions, nitrogênio e fósforo total do solo.

Observa-se que a adubação orgânica a partir de lodo de esgoto é capaz de elevar o $\mathrm{pH}$, a capacidade de troca de cátions e a saturação por cálcio do solo e diminuir a saturação por alumínio em solos de textura arenosa a média. Esses resultados são corroborados ainda por Mosquera-Losada et al. (2006) e López-Díaz et al. (2007). Percebe-se também que o efeito residual sobre a disponibilidade de potássio é menor do que para as outras bases, sendo ainda menor no solo arenoso. Isso se deve à alta mobilidade desse elemento no solo (Bertol et al., 2004). Portanto, nesse tipo de solo, pode ser necessária sua reposição antes de outros elementos.

O efeito residual da adubação orgânica sobre o pH do solo é elevado, fato esse de extrema importância para a sustentabilidade do sistema, pois a calagem em sistemas silvipastoris consolidados é realizada em superfície, o que, segundo Prado (2003), pode acarretar supercalagem e, consequentemente, em alterações eletroquímicas, originando mudanças nas cargas superficiais das partículas que influenciam a biodisponibilidade e mobilidade de nutrientes e contaminantes nos solos, a agregação das partículas e o sistema poroso do solo. Isso pode diminuir a capacidade do solo de infiltrar e armazenar água, podendo até desencadear processos de erosão do solo.

É importante monitorar o teor de metais no solo e plantas quando se utiliza lodo de esgoto como fonte de adubação. Ferreiro-Domínguez et al. (2012) constataram que com a aplicação $320 \mathrm{~kg}$ de $\mathrm{N} \mathrm{ha}^{-1}$ a partir de lodo digerido anaerobicamente não houve problemas de qualidade da água ou efeitos nocivos sobre os vegetais em sistema silvipastoril, mas quando, aplicado em sistemas florestais a disponibilidade de cobre no solo e a concentração nas plantas foram reduzidas. Rigueiro-Rodríguez et al. (2012) estudando a mesma forma e quantidade de fertilização com lodo de esgoto, verificaram aumento do total de zinco no solo ao longo do tempo, mas sem ultrapassar os limites estabelecidos pela legislação espanhola (150 $\left.\mathrm{mg} \mathrm{kg}^{-1}\right)$ e, também, sem causar efeitos prejudiciais para as plantas.

\section{Efeito da adubação orgânica sobre as característi-}




\section{cas das plantas}

Neste tópico serão abordados os estudos descritos anteriormente para o efeito nas propriedades químicas do solo, porém com relação à sua influência sobre o componente vegetal dos sistemas silvipastoris.

Mosquera-Losada et al. (2006) observaram crescimento das árvores superior ao valor médio da região estudada, tanto em altura, quanto em diâmetro. Isso se deve, provavelmente, às reservas contidas no solo terem suprido as necessidades nutricionais das plantas nos primeiros quatro anos, pois nesse período, não houve diferença $(p>0,01)$ entre a ausência e presença de adubação, seja mineral ou orgânica, no desenvolvimento das árvores. Entretanto, após sete anos de cultivo silvipastoril foi observado efeito superior ( $p$ $<0,01)$ da adubação orgânica a mineral e a ausência de adubação no desenvolvimento das árvores. Em relação à espécie forrageira, a produtividade anual foi maior $(\mathrm{p}$ $<0,01)$ com a adubação mineral, seguida da fertilização orgânica e da ausência de fertilizante.

Como o efeito residual da adubação orgânica é longo, as espécies de maior ciclo podem ser mais favorecidas. As espécies forrageiras, como são manejadas de forma mais intensa, podem ser mais beneficiadas com fontes solúveis de nutrientes de rápida liberação. Como constatado por Andrade et al. (2001), que observaram resposta no rendimento de Panicum maximum cv. Tanzânia-1 em função da adubação mineral nitrogenada. Entretanto, também pode ocorrer rendimento igual ou superior da adubação orgânica em relação a mineral (Rigueiro-Rodriguez et al., 2000; López-Díaz et al., 2009; Mosquera-Losada et al., 2010).

Rigueiro-Rodriguez et al. (2000), utilizando o mesmo resíduo (lodo de laticínio) que Mosquera-Losada et al. (2006), observaram resultado distinto. O rendimento de pastagem não diferiu entre a adubação orgânica e mineral nos primeiros cortes. Porém, a adubação mineral superou a orgânica em avaliações posteriores, provavelmente por ter sido realizada de forma parcelada, enquanto que o adubo orgânico foi aplicado em uma única parcela. Para o componente arbóreo, a adubação orgânica superou a mineral nos três anos de avaliação. As diferentes formas de adubação influenciaram também a interação entre árvores e forragem. Foi constatado que com a adubação mineral o incremento de uma tonelada de produção de pastagens reduziu a altura das árvores em 3,9 e 2,5 cm e o diâmetro em 12,2 e 7,4 mm, no primeiro e segundo ano após o plantio, respectivamente. Com a adubação orgânica o aumento da produção de pasto não modificou a produção das árvores.

O desenvolvimento da pastagem pode também ser afetado pelo manejo anterior do solo. MosqueraLosada et al. (2010) observaram que solos previamente cultivados eram mais férteis que solos sob floresta, com maior $\mathrm{pH}$ e atividade microbiana. Os autores complementaram que a maior disponibilidade de nutrientes nesses solos aumentou a produção do pasto. Contudo, mesmo em solos florestais o tratamento com lodo de esgoto foi superior à adubação mineral nos primeiros anos e também elevou a produção de forragem. Os autores atribuíram esse resultado à entrada de outros nutrientes, além de N, P e K, na adubação orgânica. Ao aplicarem $320 \mathrm{~kg}$ de $\mathrm{N} \mathrm{ha}^{-1}$ foram incorporados também 162,$74 ; 32,00 ; 247,77$ e 76,80 kg ha ${ }^{-1}$ de $\mathrm{P}, \mathrm{K}, \mathrm{Ca}$ e Mg, respectivamente, além de micronutrientes.

Como discutido na seção anterior, o uso de lodo de esgoto consiste em uma estratégia para elevar o $\mathrm{pH}$ do solo, o que se reflete também na sua relação com a planta. Mosquera-Losada et al. (2012), trabalhando com um solo de $\mathrm{pH}$ em torno de 4,0, verificaram efeito da aplicação de calcário no desenvolvimento das árvores, apenas na ausência de lodo de esgoto. Portanto, com a aplicação desse insumo orgânico, pode-se suprimir a prática da calagem mesmo em solo ácido, sem prejuízo ao desenvolvimento das plantas. De modo semelhante, Ferreiro-Domínguez et al. (2014) obtiveram maior diâmetro das árvores nos tratamentos com aplicação de lodo de esgoto, tanto na presença quanto na ausência de calcário.

Ferreiro-Domínguez et al. (2011) recomendam a aplicação de $200 \mathrm{~kg}_{\text {de }} \mathrm{N} \mathrm{ha}^{-1}$ a partir de lodo de esgoto para incrementar o desenvolvimento de espécies forrageiras e arbóreas. No entanto, a quantidade deve ser avaliada para cada caso, como observado por LópezDíaz et al. (2009) que salientaram que doses acima de $320 \mathrm{~kg}$ de $\mathrm{N} \mathrm{ha}^{-1}$ a partir de lodo de esgoto podem prejudicar o desenvolvimento de Pinus radiata.

Como discutido na seção anterior, a reposição de potássio pode ser necessária em alguns casos antes de outros elementos, devido à sua alta mobilidade no solo. Nesse enfoque, López-Díaz et al. (2009) avaliaram durante três anos consecutivos, em experimento conduzido na Espanha, três aplicações anuais de lodo de esgoto com base em uma dose total de N (160 kg 
$\mathrm{N}$ ha ${ }^{-1}$ de, $320 \mathrm{~kg} \mathrm{~N}^{-1}$ e $480 \mathrm{~kg} \mathrm{~N} \mathrm{ha}^{-1}$ ), com e sem adubação potássica (200 e $0 \mathrm{~kg}$ de $\mathrm{K}_{2} \mathrm{O}$ ha $^{-1}$ por ano), sendo utilizados dois controles: nenhuma fertilização e adubação mineral (80 kg N ha-1, $120 \mathrm{~kg}$ de $\mathrm{P}_{2} \mathrm{O}_{5}$ ha $^{-1} \mathrm{e}$ $200 \mathrm{~kg}$ de $\mathrm{K}_{2} \mathrm{O}$ ha $^{-1}$ parcelado em duas aplicações). Os autores constataram que a aplicação de lodo de esgoto em conjunto com adubação potássica aumentou o diâmetro, a altura e o volume de madeira de Pinus radiata, bem como a produção de forragem. Observaram, ainda, que a adubação orgânica pode superar a mineral para a produção de pasto.

\section{Considerações finais}

O manejo da adubação orgânica em sistemas silvipastoris é complexo, em decorrência das características intrínsecas aos resíduos utilizados como adubo e às relações ecológicas que ocorrem dentro do sistema. No entanto, pode suprir e, ou, diminuir a necessidade de calagem e fertilização mineral, com longo efeito residual e rendimentos satisfatórios, tanto do componente arbóreo, quanto do forrageiro.

O cálculo da quantidade de adubo necessária é realizado com base no conteúdo disponível (mineralizável) de macronutrientes primários, geralmente o nitrogênio. Além disso, pode ser necessária a complementação de algum nutriente por fontes minerais, devido ao baixo teor no adubo orgânico ou rápida perda do sistema. É necessário, também, o monitoramento do teor de metais pesados no adubo, no solo e nas plantas ao longo dos anos de cultivo.

As pesquisas envolvendo a temática de adubação orgânica em sistemas silvipastoris ainda são escassas e pontuais. Havendo, desse modo, a necessidade de maior número de pesquisas com ampla variação de adubos, técnicas de manejo, arranjos, espécies e condições edafoclimáticas.

\section{Referências}

Andrade, C. M. S. de. et al. Árvores de baginha (Stryphnodendron guianense (Aubl.) Benth.) em ecossistemas de pastagens cultivadas na Amazônia ocidental. Revista Brasileira de Zootecnia, v. 31, n. 2, p. 574-582, 2002. DOI: 10.1590/S1516-35982002000300006.

Andrade, C. M. S. de. et al. Fatores limitantes ao crescimento do capim-tanzânia em um sistema agrossilvipastoril com eucalipto, na região dos cerrados de Minas Gerais. Revista Brasileira de Zootecnia, v. 30, n. 4, p. 1178-1185, 2001. DOI: 10.1590/S151635982001000500007.
Andrade, F. V. et al. Adição de ácidos orgânicos e húmicos em Latossolos e adsorção de fosfato. Revista Brasileira de Ciência do Solo, v. 27, p. 1003-1011, 2003. DOI: 10.1590/S0100$06832003000600004 \#$ sthash.nFatC1tx.dpuf.

Araújo, F. F. de. et al. Lodo de esgoto na fertilidade do solo, na nutrição de Brachiaria decumbens e na atividade da desidrogenase. Pesquisa Agropecuária Tropical, v. 39, n. 1, p. 1-6, 2009.

Associação Nacional para Difusão de Adubos. Principais indicadores do setor de fertilizantes. Disponível em: $<\mathrm{http}: / /$ anda. org.br/index.php?mpg=03.00.00\&ver=por $>$. Acesso em: 9 ago. 2016.

Barreiros, R. M. et al. Modificações na produtividade e nas características físicas e químicas da madeira de Eucalyptus grandis causadas pela adubação com lodo de esgoto tratado. Revista Árvore, v. 31, n. 1, p. 103-111, 2007. DOI: 10.1590/S010067622007000100012 .

Behera, B. C. et al. Diversity, mechanism and biotechnology of phosphate solubilising microorganism in mangrove: a review. Biocatalysis and Agricultural Biotechnology, v. 3, p. 97-110, 2014. DOI: 10.1016/j.bcab.2013.09.008.

Bernardino, F. S. \& Garcia, R. Sistemas silvipastoris. Pesquisa Florestal Brasileira, n. 60, p. 77-87, 2009. DOI: 10.4336/2009. pfb.60.77.

Bertol, I. et al. Perdas de fósforo e potássio por erosão hídrica em um Inceptisol sob chuva natural. Revista Brasileira de Ciência do Solo, v. 28, n. 3, p. 485-494, 2004. DOI: 10.1590/S010006832004000300010 .

Boeira, R. C. \& Maximiliano, V. C. B. Mineralização de compostos nitrogenados de lodos de esgoto na quinta aplicação em Latossolo. Revista Brasileira de Ciência do Solo, v. 33, p. 711-722, 2009. DOI: 10.1590/S0100-06832009000300023.

Boeira, R. C. et al. Mineralização de nitrogênio em solo tropical tratado com lodos de esgoto. Pesquisa Agropecuária Brasileira, v. 37, n. 11, p. 1639-1647, 2002. DOI: 10.1590/S0100204X2002001100016.

Brasil. Conselho Nacional do Meio Ambiente. Resolução nº. 375, de 29 de agosto de 2006. Define critérios e procedimentos, para o uso agrícola de lodos de esgoto gerados em estações de tratamento de esgoto sanitário e seus produtos derivados, e dá outras providências. Diário Oficial [da] República Federativa do Brasil, Brasília, DF, n. 167 , p. $141-146,30$ out. 2006.

Carvalho, M. M. \& Xavier, D. F. Sistemas silvipastoris para recuperação e desenvolvimento de pastagens. In: Aquino, A. A. de \& Assis, R. L. de. (Ed.). Agroecologia: princípios e técnicas para uma agricultura sustentável. Brasília, DF: Embrapa Informação Tecnológica, 2005. p. 497-517.

Chiaradia, J. J. et al. Produtividade e nutrição de mamona cultivada em área de reforma de canavial tratada com lodo de esgoto. Revista Brasileira de Ciência do Solo, v. 33, n. 3, p. 701-709, 2009. DOI: 10.1590/S0100-06832009000300022.

Ferreiro-Domínguez, N. et al. Effect of lime and sewage sludge fertilisation on tree and understory interaction in a silvopastoral system. Agriculture, Ecosystems and Environment, v. 188, p. 72-79, 2014. DOI: 10.1016/j.agee.2014.02.007. 
Ferreiro-Domínguez, N. et al. Response to sewage sludge fertilisation in a Quercus rubra L. silvopastoral system: soil, plant biodiversity and tree and pasture production. Agriculture, Ecosystems and Environment, v. 141, p. 49-57, 2011. DOI: 10.1016/j. agee.2011.02.009.

Ferreiro-Domínguez, N. et al. R. Sewage sludge fertiliser use: implications for soil and plant copper evolution in forest and agronomic soils. Science of the Total Environment, v. 424, p. 3947, 2012. DOI: 10.1016/j.scitotenv.2012.02.042.

Giacomini, S. J. et al. Carbon and nitrogen mineralization in soil combining sewage sludge and straw. Revista Brasileira de Ciência do Solo, v. 39, p. 1428-1435, 2015. DOI: $10.1590 / 01000683$ rbcs20140324.

Havlin, J. L. et al. Soil fertility and fertilizers: an introduction to nutrient management. 7th ed. New Jersey: Pearson, 2005. 515 p.

Joffre, R. et al. The dehesa: an agrosilvopastoral system of the Mediterranean region with special reference to the Sierra Morena area of Spain. Agroforestry Systems, v. 6, p. 71-96, 1998. DOI: 10.1007/BF02220110.

Lal, R. Soil carbon sequestration impacts on global climate change and food security. Science, v. 304, p. 1623-1627, 2004. DOI: 10.1126/ science.1097396.

Li, W. \& Johnson, C. E. Relationships among pH, aluminum solubility and aluminum complexation with organic matter in acid forest soils of the Northeastern United States. Geoderma, v. 271, n. 1, p. 234-242, 2016. DOI: 10.1016/j.geoderma.2016.02.030.

Lima, J. J. de. et al. Influência da adubação orgânica nas propriedades químicas de um Latossolo Vermelho distrófico e na produção de matéria seca de Brachiaria brizantha cv. Marandu. Acta Scientiarum Agronomy, v. 29, supl. p. 715-719, 2007. DOI: 10.4025/actasciagron.v29i5.754.

Lopes, A. S. et al. Guia de fertilidade do solo. Lavras: Universidade Federal de Lavras, 2004. 501 p. Versão multimídia.

López-Díaz, M. L. et al. Influence of pasture botanical composition and fertilization treatments on tree growth. Forest Ecology and Management, v. 257, p. 1363-1372, 2009. DOI: 10.1016/j. foreco.2008.12.001.

López-Díaz, M. L. et al. Lime, sewage sludge and mineral fertilization in a silvopastoral system developed in very acid soils. Agroforestry Systems, v. 70, n. 1, p. 91-101, 2007. DOI: 10.1007/ s10457-007-9046-9.

Mosquera-Losada, M. R. et al. Fertilization in pastoral and Pinus radiata D. Don silvopastoral systems developed in forest and agronomic soils of Northwest Spain. Agriculture, Ecosystems and Environment, v. 139, p. 618-628, 2010. DOI: 10.1016/j. agee.2010.10.007.
Mosquera-Losada, M. R. et al. Pasture, tree and soil evolution in silvopastoral systems of Atlantic Europe. Forest Ecology and Management, v. 232, p. 135-145, 2006. DOI: 10.1016/j. foreco.2006.05.057.

Mosquera-Losada, M. R. et al. Residual effects of lime and sewage sludge inputs on soil fertility and tree and pasture production in a Pinus radiata D. Don silvopastoral system established in a very acidic soil. Agriculture, Ecosystems and Environment, v. 161, p. 165-173, 2012. DOI: 10.1016/j.agee.2012.08.001.

Nair, P. K. R. (Ed.). Agroforestry systems in the tropic. Dordrecht: Kluwer Academic Publishers-ICRAF, 1989. 664 p.

Oliveira, T. K. et al. Sistemas silvipastoris: conceitos, benefícios e métodos de implantação. In: Andrade, C. M. S. et al. (Ed.). Guia arbopasto: manual de identificação e seleção de espécies arbóreas para sistemas silvipastoris. Brasília, DF: Embrapa, 2012. 345 p.

Plese, L. P. de M. Legislação ambiental: normas brasileiras para resíduos. In: Teixeira, S. T. et al. (Ed.). Recomendações para a gestão de resíduos sólidos no Estado do Acre. Porto Velho: Núcleo Regional Noroeste da Sociedade Brasileira de Ciência do Solo, 2015. p. 143-163.

Prado, R. de M. A calagem e as propriedades físicas de solos tropicais: revisão de literatura. Revista Biociências, v. 9, n. 3, p. 7-16, 2003.

Rigueiro-Rodríguez, A. et al. Pasture and soil zinc evolution in forest and agriculture soils of Northwest Spain three years after fertilization with sewage sludge. Agriculture, Ecosystems and Environment, v. 150, p. 111-120, 2012. DOI: 10.1016/j.agee.2012.01.018.

Rigueiro-Rodríguez, A. et al. Pasture production and tree growth in a young pine plantation fertilized with inorganic fertilizers and milk sewage in northwestern Spain. Agroforestry Systems, v. 48, n. 3, p. 245-256, 2000. DOI: 10.1023/A:1006233204645.

Scheffer-Basso, S. M. et al. Resposta de pastagens perenes à adubação com chorume suíno: pastagem natural. Revista Brasileira de Zootecnia, v. 37, n. 2, p. 221-227, 2008. DOI: 10.1590/S151635982008000200007 .

Tasca, F. A. et al. Volatilização de amônia do solo após a aplicação de ureia convencional ou com inibidor de urease. Revista Brasileira de Ciência do Solo, v. 35, p. 493-502, 2011. DOI: 10.1590/S010006832011000200018.

Teixeira, S. T. Aplicação de resíduos em solos agrícolas: alternativa para o desenvolvimento sustentável. In: Teixeira, S. T. et al. (Ed.). Recomendações para a gestão de resíduos sólidos no Estado do Acre. Porto Velho: Núcleo Regional Noroeste da Sociedade Brasileira de Ciência do Solo, 2015. p. 1-10. 